\title{
Tumor Microenvironment Conditioning by Abortive Lytic Replication of Oncogenic -Herpesviruses
}

\author{
Münz, Christian
}

\begin{abstract}
Epstein Barr virus (EBV) and Kaposi sarcoma-associated herpesvirus (KSHV) constitute the human -herpesviruses and two of the seven human tumor viruses. In addition to their viral oncogenes that primarily belong to the latent infection programs of these viruses, they encode proteins that condition the microenvironment. Many of these are early lytic gene products and are only expressed in a subset of infected cells of the tumor mass. In this chapter I will describe their function and the evidence that targeting them in addition to the latent oncogenes could be beneficial for the treatment of EBV-and KSHV-associated malignancies.
\end{abstract}

DOI: https://doi.org/10.1007/978-3-030-35727-6_9

Posted at the Zurich Open Repository and Archive, University of Zurich ZORA URL: https://doi.org/10.5167/uzh-198969

Book Section

Accepted Version

Originally published at:

Münz, Christian (2020). Tumor Microenvironment Conditioning by Abortive Lytic Replication of Oncogenic -Herpesviruses. In: Birbrair, Alexander. Tumor Microenvironment. Cham: Springer, 127-135.

DOI: https://doi.org/10.1007/978-3-030-35727-6_9 


\section{Tumor microenvironment conditioning by abortive lytic replication of oncogenic $\gamma$-herpesviruses}

Christian Münz

Viral Immunobiology, Institute of Experimental Immunology, University of Zürich, Zürich, Switzerland

Please address correspondence to: Christian Münz, Viral Immunobiology, Institute of Experimental Immunology, University of Zürich, Winterthurerstrasse 190, CH-8057 Zürich, e-mail: christian.muenz@uzh.ch, Tel.: +41 44635 3716,Fax: +41446356883

Keywords: Kaposi sarcoma associated herpesvirus, Epstein Barr virus, viral IL-6, viral IL-10, viral MIP, viral miRNA, CCL5, lytic replication, angiogenesis, Kaposi sarcoma, primary effusion lymphoma, multicentric Castleman's disease, Hodgkin's lymphoma, Burkitt's lymphoma, nasopharyngeal carcinoma 


\begin{abstract}
Epstein Barr virus (EBV) and Kaposi sarcoma associated herpesvirus (KSHV) constitute the human $\gamma$-herpesviruses and two of the seven human tumor viruses. In addition to their viral oncogenes that primarily belong to the latent infection programs of these viruses, they encode proteins that condition the microenvironment. Many of these are early lytic gene products and are only expressed in a subset of infected cells of the tumor mass. In this chapter I will describe their function and the evidence that targeting them in addition to the latent oncogenes could be beneficial for the treatment of EBV and KSHV associated malignancies.
\end{abstract}




\section{Introduction to human $\gamma$-herpesviruses}

Among human herpesviruses, oncogenesis is confined to the $\gamma$-herpesviridae (1). These contain the lymphocryptovirus Epstein Barr virus (EBV) or human herpesvirus 4 (HHV4), and the rhadinovirus Kaposi sarcoma associated herpesvirus (KSHV) or human herpesvirus 8 (HHV8). Both viruses share a tropism for human B cells and stimulate these into lymphoproliferations in some of which even both viruses are present at the same time (2). In addition they are, however, also associated with tumors that originate from other cell types, including epithelial, NK/T and smooth muscle cells for EBV, and endothelial cell for $\operatorname{KSHV}(3,4)$. The oncogenic potential of these two viruses is thought to originate from their need to differentiate $B$ cells into long-lived memory compartments for persistence, memory B cells for EBV and plasma cells for KSHV (4, 5). These B cells get infected by the two viruses in sub-mucosal secondary lymphoid tissues after transmission via saliva exchange and possibly transcytosis across the mucosal epithelium (6). Latent infection by the two viruses is then thought to lead to $B$ cell activation and proliferation. For EBV mainly eight latent gene products, more than forty miRNAs and two EBV encoded small RNAs (EBERs) are involved in this task (5). Differentiation from this activated $B$ cell stage to memory B cells by follicular and extrafollicular routes allows for EBV persistence without any viral protein expression $(7,8)$. KSHV contains also three latent gene products which together with the viral miRNAs induce B cell proliferation after overexpression in mice (9). In addition, however, expression of some lytic KSHV gene products without overt infectious particle production augments $B$ cell activation and differentiation, like the plasmablast or plasma cell differentiation that is induced by viral IL-6 (vIL-6) expression from the K2 locus (2). B cell proliferations that are driven by these viral programs can be found in human immunodeficiency virus (HIV) infected patients with acquired immunodeficiency syndrome (AIDS) as immunoblastic lymphoma that is associated with all EBV latent gene expression and multicentric Castleman's disease (MCD) that is associated with latent KSHV gene expression but also some lytic KSHV virus production (10, 11). These programs extensively shape the phenotype of the infected $B$ cells to activated lymphoblasts by EBV and plasmablasts by KSHV, as well as modify their B cell receptor, introducing addition somatic hypermutation in the case of EBV, and switch to $\lambda$ light chain expression in the case of $\operatorname{KSHV}(12,13)$. From these stages both extrafollicular and germinal center dependent routes most likely lead to persistence with no viral protein and only viral nontranslated RNA expression. At least EBV expresses a restricted set of latent proteins in centroblast and centrocytes to rescue infected B cells from cell death in germinal centers (14). From this reservoir both viruses reactivate into lytic infectious particle replication upon plasma cell differentiation for EBV and most likely also in plasma cells for $\operatorname{KSHV}(11,15)$. If this occurs at 
submucosal secondary lymphoid tissues, infectious virus can find its way into the saliva for further transmission, possibly after an additional amplification in mucosal epithelial cells at least for EBV (16). These lifecycles of EBV and KSHV utilize B cell immunobiology to both disseminate in their host, establish persistence in long-lived cells and allow reactivation in submucosal tissues for further transmission.

However, this lifestyle also forces them to induce B cell lymphoproliferations and channel infected cells through differentiation stages with increased somatic mutations. The oncogenic capacity of EBV and KSHV gene products and host gene mutations that emerge in the process of B cell differentiation lead to tumors associated with the two $\gamma$-herpesviruses. In this chapter I will discuss the different EBV and KSHV associated malignancies and how their microenvironments are conditioned for both pro-proliferative and immune evasive functions. 


\section{Classical oncogenes of EBV and KSHV}

EBV is associated with tumors of $\mathrm{B}$, epithelial, NK/T and smooth muscle cell origin (3). In these malignancies, EBV expresses a variable amount of latent viral proteins and the respective gene expression patterns are called latencies I, II and III. B cell derived immunoblastic lymphomas and post-transplant lymphoproliferative diseases (PTLDs) express all 8 latent EBV genes and are primarily observed during severe immune suppression, for example during advanced HIV infection and iatrogenic immune system inhibition (17). EBV associated smooth muscle tumors harbor also latency III (18). Latency II tumors like Hodgkin's lymphoma of B cell origin and nasopharyngeal carcinoma of epithelial cell origin express only one of the six nuclear antigens of EBV (EBNAs), namely EBNA1, and the two latent membrane proteins LMP1 and $2(1,19)$. This latency II or even less latent viral protein expression can also be found in NK/T cell lymphomas that are associated with EBV (20). Finally, only EBNA1 is expressed in latency I which is found in Burkitt's lymphoma and primary effusion lymphoma (PEL), the latter being in the majority of cases also co-infected with KSHV (1). In contrast to these distinct latent EBV gene expression patterns, KSHV rarely expresses only its three latent viral proteins, latency-associated nuclear antigen (LANA), viral FLICE-like inhibitory protein (vFLIP) and viral cyclin (vCYC), and viral miRNAs (4). The adjacent kaposin locus $\mathrm{K} 12$ is also often expressed, as well as in decreasing frequency the $\mathrm{K} 15$, the $\mathrm{K} 2$ and the non-translated polyadenylated nuclear RNA (PAN) encoding KSHV genome region $(21,22)$. This variable gene expression is seen in both endothelial and $B$ cell derived tumors that are associated with KSHV, namely Kaposi sarcoma or multicentric Castleman's disease (MCD) and PEL (23-25). It might represent a variable frequency of cells undergoing abortive and productive lytic KSHV replication in the respective tumors (26). Thus, variable viral gene expression patterns can be observed in $\gamma$-herpesvirus associated malignancies. These segregate with tumor entities for EBV and subdivide tumor entities for KSHV.

Both viruses contain bona fide oncogenes, which upon expression in mice cause tumors. This has been shown for the viral latency locus and vFLIP of $\operatorname{KSHV}(9,27,28)$, and for EBNA1 and LMP1 of EBV $(29,30)$. Interestingly, both viruses activate c-myc and NF- $\mathrm{B} B$ to induce B cell activation and proliferation. EBV achieves this via EBNA2 assisted c-myc transcription (31) and LMP1 mediated constitutive NF-אB activation (32). In some EBV associated lymphomas that express only EBNA1 the c-myc expression is achieved by cellular mutations that are thought to compensate for EBNA2 absence, like c-myc translocation into the immunoglobulin loci for Burkitt's lymphoma (33) and c-myc gene amplification in lymphomas that emerge in mice upon EBNA1 expression in B cells (34). For KSHV, LANA amplifies c-myc activity $(35,36)$ and vFLIP activates $\mathrm{NF}-\kappa \mathrm{B}(37,38)$. These pro-proliferative functions are paired with anti-apoptotic mechanisms, such 
as for EBV the EBNA3C mediated inhibition of pro-apoptotic $\mathrm{p} 16^{\mathrm{INK} 4 \mathrm{a}}$ and BIM expression $(39,40)$ and the pro-survival B cell receptor like signaling of LMP2 (41). In PEL the p16INK4a locus is sometimes mutated to presumably compensate for the absence of an active mechanism to suppress this pro-apoptotic protein, which is induced by the cell cycle driving activity of vCYC (42). One can also speculate that the B cell receptor modifying activities, somatic hypermutation by EBNA3C mediated activation induced deaminase (AID) induction (12) and $\lambda$ chain usage driven by VFLIP (28), might improve tonic signaling for infected B cell survival, similarly to LMP2 function. In addition to these immunoblastic features of latent EBV and KSHV infection, the leaky lytic KSHV gene product expression, mainly from the K2 locus encoding vIL-6 (Figure 1) induces plasma cell features in MCD and PEL $(43,44)$. However, the functions of latent $\gamma$-herpesvirus proteins and leaky presumably abortive lytic gene expression go much further than just transforming EBV and KSHV infected cells. They also heavily condition the microenvironment of the associated tumors and this regulation will be discussed next. 


\section{Conditioning of the tumor microenvironment by lytic and latent EBV and KSHV gene expression}

During their co-evolution with the human host both EBV and KSHV have reached a stalemate with the immune system that in the vast majority of the more than $90 \%$ of adults that are persistently infected with EBV and of the more than $75 \%$ of adults that have encountered KSHV in some sub-Saharan countries leads to persistence of both viruses, but also does not cause pathology $(45,46)$. On the contrary KSHV and EBV seem to even promote this equilibrium. For example, EBV encodes with EBNA3B a tumor suppressor (47). This latent viral nuclear antigen induces transcription of CXCL9 and 10, two inflammatory chemokines that recruit lymphocytes via their CXCR3 receptor. EBV deficient in EBNA3B causes lymphomas at increased frequencies with diminished inflammatory infiltrates, and restoration of CXCL10 secretion by transfection also reinstalls T cell mediated immune control of lymphoma cells with EBNA3B deficient EBV. Not only latent gene products, but also early lytic EBV proteins foster leucocyte recruitment to the vicinity of infected cells (Figure 1). Along these lines CCL5 production has been reported in lymphomas with higher lytic EBV replication (48). This chemokine facilitates macrophage recruitment via CCR5 binding into the tumor microenvironment (49). Similarly, KSHV encodes three macrophage inflammatory protein (MIP) homologues (vCCL1-3) as early lytic gene products. These are thought to recruit myeloid cells into the microenvironment of KSHV infected cells via CCR8 (vCCL1 and 2) and XCR1 (vCCL3) (50). These inflammatory infiltrates protect persistently EBV and KSHV infected hosts probably most of the time from $\gamma$-herpesvirus associated pathologies.

However, in virus associated tumors these infiltrates are turned into tumor cell nurturing and immunosuppressive leucocytes. Along these lines EBV encodes viral IL-10 $(51,52)$ and KSHV associated lymphomas are also dominated by IL-10 production (53). IL-10 suppresses T cell mediated restriction of EBV transformed B cells $(54,55)$ (Figure 1$)$. In addition, tumor cells as well as inflammatory infiltrates produce TGF- $\beta$ in Hodgkin's lymphoma (56), which is presumably involved in the induction of regulatory T cells rosetting around the malignant Reed-Sternberg cells in this tumor entity (57). Furthermore, EBV encoded viral miRNAs also compromise MHC class I restricted antigen presentation to $\mathrm{CD}^{+} \mathrm{T}$ cells and their CXCL11 mediated attraction into the tumor microenvironment (58-61), further dampening T cell mediated immune control (Figure 1). While EBV miRNAs compromise MHC restricted antigen presentation both during latency and lytic replication, early lytic gene products of both viruses further compromise MHC class I restricted $\mathrm{CD}^{+} \mathrm{T}$ cell stimulation. These are the KSHV K3 and $\mathrm{K} 5$ gene products that downregulate MHC class I molecules (62) and the EBV BGLF5, BNLF2a and BILF1 gene products that inhibit MHC class I transcription, peptide loading and surface expression, respectively (63). Both 
viruses contain with KSHV vIRF1-4 and EBV BZLF1, BRLF1 and BGLF4 also lytic gene products that block interferon signaling $(46,63)$, but at least for EBV there is little evidence that type I IFN influences its infection in vivo (64). Thus, lytic gene expression of $\gamma$-herpesviruses in a subset of cells in the associated tumors and often not resulting in productive replication of infectious particles, conditions the respective tumor microenvironment to be immune suppressive and amplifies this immune suppression by infiltrating leucocyte polarization.

In addition to immune modulation in the tumor microenvironment, lytic KSHV gene products also contributes to angiogenesis and thereby further supports tumor growth. KSHV G protein-coupled receptor (VGPCR), K1 and K15 stimulate angiogenic factors, such as vascular endothelial growth factor (VEGF), platelet-derived growth factor (PDGF) and angiopoietin 2 (ANGPT2) $(26,46)$ (Figure 1). This pro-angiogenic functions of KSHV might be an adaptation to the viral life cycle in endothelial cells, giving rise to Kaposi sarcoma, even so it remains unclear why KSHV requires endothelial cell infection for persistence. 


\section{Targeting lytic replication for the treatment of EBV and KSHV associated malignancies}

Even so lytic viral replication induction should intuitively destroy tumor cells, the above discussed contributions of early lytic gene products to paracrine microenvironment conditioning for optimal tumor growth might make it attractive to inhibit lytic $\gamma$-herpesvirus infection as a treatment for EBV and KSHV associated malignancies. Along these lines EBV deficient in lytic infection induction causes less tumors in mice with from $\mathrm{CD} 34^{+}$hematopoietic progenitor cells reconstituted human immune system compartments (humanized mice) $(65,66)$. Furthermore, EBV strains with increased lytic replication are enriched in malignancies that are associated with this virus (67-69). Similarly in KSHV associated MCD, inhibition of the lytic cycle associated viral DNA polymerase with a combination of zidovudine and valganciclovir was clinically efficacious in the majority of cases (70). Furthermore, in HIV infected individuals that were treated with the herpesviral DNA polymerase inhibitor ganciclovir for human cytomegalovirus (HCMV) reactivation Kaposi sarcoma incidence was significantly reduced $(71,72)$. Finally, herpesviral DNA polymerase inhibition has also been successful in individual cases of PELs (73). These studies indicate that lytic EBV and KSHV replication might enhance virus associated tumorigenesis and should be targeted for treatment.

However, instead of inhibition of overall lytic $\gamma$-herpesviral infection, individual effects of lytic EBV and KSHV gene expression can also be targeted. Along these lines CCR5 that has been suggested to mediate recruitment of myeloid cell into the tumor microenvironment of Hodgkin's lymphoma has been inhibited with maraviroc in combination with blocking antibodies against its ligand CCL5 (74). CCL5 is thought to be elicited by early lytic EBV infection (48). Blocking CCL5 binding to CCR5 inhibited Hodgkin's lymphoma growth in a xenograft model. Similarly, VEGF that is induced by KHSV vGPCR, K1 and K15 has been blocked with the recombinant antibody bevacizumab in Kaposi sarcoma patients (75). This led to a clinical response in around $30 \%$ of treated individuals. Furthermore, the early lytic KSHV gene product vIL-6 is thought to drive plasma cell differentiation in MCD and PEL (2). Plasma cell differentiation renders tumors susceptible to proteasome inhibition, as seen for multiple myeloma (76). Indeed, combining the proteasome inhibitor bortezomib with chemotherapy successfully treated PEL in one patient (77). IL-6 receptor was also directly targeted for treatment of MCD with clinical efficacy in a few patients $(78,79)$. These initial encouraging results suggest that also individual lytic $\gamma$-herpesvirus gene products and their effects can be inhibited for therapeutic benefit.

These individual lytic EBV and KSHV proteins can also be used as active or passive vaccine antigens to target the above discussed paracrine functions. Along these lines the protective value of late lytic EBV antigen specific $\mathrm{CD} 4^{+} \mathrm{T}$ cell responses have been explored in a 
humanized mouse model (80). The respective viral antigens also sensitized neighboring latently infected cells for $\mathrm{CD}^{+} \mathrm{T}$ cell recognition after transfer from the subset of lytically EBV replicating cells. However, in active vaccination with EBV derived viral particles addition of the latent EBNA1 antigen improved protective vaccine efficacy (81). Nevertheless, lytic EBV antigens should be considered in combination with latent antigens for an optimal vaccine formulation to elicit protective T cell responses. 


\section{Conclusions and future outlook}

Human $\gamma$-herpesviruses contain some of the most oncogenic pathogens. Apart from their oncogenes, some of the EBV and KSHV associated malignancies, however, heavily rely also on their inflammatory infiltrates to sustain tumor growth. This is probably most dramatic in Hodgkin's lymphoma in which only around $1 \%$ of the tumor mass represents the malignant Reed-Sternberg cells (57). It has become apparent in the recent years that paracrine conditioning of this tumor microenvironment by a small subset of cells undergoing lytic $\gamma$-herpesvirus infection serves functions in the recruitment of immune cells, immune suppression and angiogenesis. We now need to capitalize on these findings for new treatments of EBV and KSHV associated malignancies that are more specific for these viruses than B cell depletion and overall inhibition of herpesviral DNA polymerases. 


\section{Acknowledgements}

Research in my laboratory is supported by Cancer Research Switzerland (KFS-4091-02-2017), KFSP-Precision ${ }^{\mathrm{MS}}$ of the University of Zurich, the Vontobel Foundation, the Baugarten Foundation, the Sobek Foundation, the Swiss Vaccine Research Institute, the Swiss MS Society, Roche, ReiThera and the Swiss National Science Foundation (310030B_182827 and CRSII5_180323). 


\section{References}

1. Cesarman E. Gammaherpesviruses and lymphoproliferative disorders. Annu Rev Pathol. 2014;9:349-72.

2. Oksenhendler E, Boutboul D, Galicier L. Kaposi sarcoma-associated herpesvirus/human herpesvirus 8-associated lymphoproliferative disorders. Blood. 2019;133(11):1186-90.

3. Kutok JL, Wang F. Spectrum of Epstein-Barr virus-associated diseases. Annu Rev Pathol. 2006;1:375-404.

4. Mariggio G, Koch S, Schulz TF. Kaposi sarcoma herpesvirus pathogenesis. Philos Trans R Soc Lond B Biol Sci. 2017;372(1732).

5. Münz C. Latency and lytic replication in the oncogenesis of the Epstein Barr virus. Nat Rev Micobiol. 2019;in press.

6. Tugizov SM, Herrera R, Palefsky JM. Epstein-Barr virus transcytosis through polarized oral epithelial cells. J Virol. 2013;87(14):8179-94.

7. Murer A, McHugh D, Caduff N, Kalchschmidt JS, Barros MH, Zbinden A, et al. EBV persistence without its EBNA3A and 3C oncogenes in vivo. PLoS Pathog. 2018;14(4):e1007039.

8. Babcock GJ, Decker LL, Volk M, Thorley-Lawson DA. EBV persistence in memory B cells in vivo. Immunity. 1998;9(3):395-404.

9. Sin SH, Dittmer DP. Viral latency locus augments B-cell response in vivo to induce chronic marginal zone enlargement, plasma cell hyperplasia, and lymphoma. Blood. 2013;121(15):295263.

10. Totonchy J, Cesarman E. Does persistent HIV replication explain continued lymphoma incidence in the era of effective antiretroviral therapy? Curr Opin Virol. 2016;20:71-7.

11. Oksenhendler E, Carcelain G, Aoki Y, Boulanger E, Maillard A, Clauvel JP, et al. High levels of human herpesvirus 8 viral load, human interleukin-6, interleukin-10, and $C$ reactive protein correlate with exacerbation of multicentric castleman disease in HIV-infected patients. Blood. 2000;96(6):2069-73.

12. Kalchschmidt JS, Bashford-Rogers R, Paschos K, Gillman AC, Styles CT, Kellam P, et al. Epstein-Barr virus nuclear protein EBNA3C directly induces expression of AID and somatic mutations in B cells. J Exp Med. 2016;213(6):921-8.

13. Totonchy J, Osborn JM, Chadburn A, Nabiee R, Argueta L, Mikita G, et al. KSHV induces immunoglobulin rearrangements in mature B lymphocytes. PLoS Pathog. 2018;14(4):e1006967. 14. Babcock JG, Hochberg D, Thorley-Lawson AD. The expression pattern of Epstein-Barr virus latent genes in vivo is dependent upon the differentiation stage of the infected B cell. Immunity. 2000;13(4):497-506. 
15. Laichalk LL, Thorley-Lawson DA. Terminal differentiation into plasma cells initiates the replicative cycle of Epstein-Barr virus in vivo. J Virol. 2005;79(2):1296-307.

16. Tugizov SM, Berline JW, Palefsky JM. Epstein-Barr virus infection of polarized tongue and nasopharyngeal epithelial cells. Nat Med. 2003;9(3):307-14.

17. Gottschalk S, Rooney CM, Heslop HE. Post-transplant lymphoproliferative disorders. Annu Rev Med. 2005;56:29-44.

18. Ong KW, Teo M, Lee V, Ong D, Lee A, Tan CS, et al. Expression of EBV latent antigens, mammalian target of rapamycin, and tumor suppression genes in EBV-positive smooth muscle tumors: clinical and therapeutic implications. Clin Cancer Res. 2009;15(17):5350-8.

19. Tsao SW, Tsang CM, Pang PS, Zhang G, Chen H, Lo KW. The biology of EBV infection in human epithelial cells. Semin Cancer Biol. 2012;22(2):137-43.

20. Fox CP, Shannon-Lowe C, Rowe M. Deciphering the role of Epstein-Barr virus in the pathogenesis of T and NK cell lymphoproliferations. Herpesviridae. 2011;2:8.

21. Rose TM, Bruce AG, Barcy S, Fitzgibbon M, Matsumoto LR, Ikoma M, et al. Quantitative RNAseq analysis of Ugandan KS tumors reveals KSHV gene expression dominated by transcription from the LTd downstream latency promoter. PLoS Pathog. 2018;14(12):e1007441. 22. Tso FY, Kossenkov AV, Lidenge SJ, Ngalamika O, Ngowi JR, Mwaiselage J, et al. RNASeq of Kaposi's sarcoma reveals alterations in glucose and lipid metabolism. PLoS Pathog. 2018;14(1):e1006844.

23. Parravicini C, Chandran B, Corbellino M, Berti E, Paulli M, Moore PS, et al. Differential viral protein expression in Kaposi's sarcoma-associated herpesvirus-infected diseases: Kaposi's sarcoma, primary effusion lymphoma, and multicentric Castleman's disease. Am J Pathol. 2000;156(3):743-9.

24. Jenner RG, Alba MM, Boshoff C, Kellam P. Kaposi's sarcoma-associated herpesvirus latent and lytic gene expression as revealed by DNA arrays. J Virol. 2001;75(2):891-902.

25. McHugh D, Caduff N, Barros MHM, Rämer P, Raykova A, Murer A, et al. Persistent KSHV infection increases EBV-associated tumor formation in vivo via enhanced EBV lytic gene expression. Cell Host \& Microbe. 2017;22(1):61-73.

26. Mesri EA, Cesarman E, Boshoff C. Kaposi's sarcoma and its associated herpesvirus. Nat Rev Cancer. 2010;10(10):707-19.

27. Sin SH, Kim Y, Eason A, Dittmer DP. KSHV Latency Locus Cooperates with Myc to Drive Lymphoma in Mice. PLoS Pathog. 2015;11(9):e1005135. 
28. Ballon G, Chen K, Perez R, Tam W, Cesarman E. Kaposi sarcoma herpesvirus (KSHV) vFLIP oncoprotein induces $B$ cell transdifferentiation and tumorigenesis in mice. J Clin Invest. 2011;121(3):1141-53.

29. Wilson JB, Bell JL, Levine AJ. Expression of Epstein-Barr virus nuclear antigen-1 induces B cell neoplasia in transgenic mice. Embo J. 1996;15(12):3117-26.

30. Kulwichit W, Edwards RH, Davenport EM, Baskar JF, Godfrey V, Raab-Traub N. Expression of the Epstein-Barr virus latent membrane protein 1 induces $B$ cell lymphoma in transgenic mice. Proc Natl Acad Sci U S A. 1998;95(20):11963-8.

31. Kempkes B, Ling PD. EBNA2 and Its Coactivator EBNA-LP. Curr Top Microbiol Immunol. 2015;391:35-59.

32. Kieser A, Sterz KR. The Latent Membrane Protein 1 (LMP1). Curr Top Microbiol Immunol. 2015;391:119-49.

33. Thorley-Lawson DA, Allday MJ. The curious case of the tumour virus: 50 years of Burkitt's lymphoma. Nat Rev Microbiol. 2008;6(12):913-24.

34. AlQarni S, Al-Sheikh Y, Campbell D, Drotar M, Hannigan A, Boyle S, et al. Lymphomas driven by Epstein-Barr virus nuclear antigen-1 (EBNA1) are dependant upon Mdm2. Oncogene. 2018.

35. Bubman D, Guasparri I, Cesarman E. Deregulation of c-Myc in primary effusion lymphoma by Kaposi's sarcoma herpesvirus latency-associated nuclear antigen. Oncogene. 2007;26(34):4979-86.

36. Liu J, Martin HJ, Liao G, Hayward SD. The Kaposi's sarcoma-associated herpesvirus LANA protein stabilizes and activates C-Myc. J Virol. 2007;81(19):10451-9.

37. Chaudhary PM, Jasmin A, Eby MT, Hood L. Modulation of the NF-kappa B pathway by virally encoded death effector domains-containing proteins. Oncogene. 1999;18(42):5738-46.

38. Sun Q, Zachariah S, Chaudhary PM. The human herpes virus 8-encoded viral FLICEinhibitory protein induces cellular transformation via NF-kappaB activation. J Biol Chem. 2003;278(52):52437-45.

39. Paschos K, Parker GA, Watanatanasup E, White RE, Allday MJ. BIM promoter directly targeted by EBNA3C in polycomb-mediated repression by EBV. Nucleic Acids Res. 2012;40(15):7233-46.

40. Skalska L, White RE, Parker GA, Turro E, Sinclair AJ, Paschos K, et al. Induction of $\mathrm{p} 16$ (INK4a) is the major barrier to proliferation when Epstein-Barr virus (EBV) transforms primary B cells into lymphoblastoid cell lines. PLoS Pathog. 2013;9(2):e1003187. 
41. Cen O, Longnecker R. Latent Membrane Protein 2 (LMP2). Curr Top Microbiol Immunol. 2015;391:151-80.

42. Platt G, Carbone A, Mittnacht S. p16INK4a loss and sensitivity in KSHV associated primary effusion lymphoma. Oncogene. 2002;21(12):1823-31.

43. Klein U, Gloghini A, Gaidano G, Chadburn A, Cesarman E, Dalla-Favera R, et al. Gene expression profile analysis of AIDS-related primary effusion lymphoma (PEL) suggests a plasmablastic derivation and identifies PEL-specific transcripts. Blood. 2003;101(10):4115-21.

44. Jenner RG, Maillard K, Cattini N, Weiss RA, Boshoff C, Wooster R, et al. Kaposi's sarcoma-associated herpesvirus-infected primary effusion lymphoma has a plasma cell gene expression profile. Proc Natl Acad Sci U S A. 2003;100(18):10399-404.

45. Farrell PJ. Epstein-Barr Virus and Cancer. Annu Rev Pathol. 2019;14:29-53.

46. Cesarman E, Damania B, Krown SE, Martin J, Bower M, Whitby D. Kaposi sarcoma. Nat Rev Dis Primers. 2019;5(1):9.

47. White RE, Ramer PC, Naresh KN, Meixlsperger S, Pinaud L, Rooney C, et al. EBNA3Bdeficient EBV promotes B cell lymphomagenesis in humanized mice and is found in human tumors. J Clin Invest. 2012;122(4):1487-502.

48. Arvey A, Ojesina AI, Pedamallu CS, Ballon G, Jung J, Duke F, et al. The tumor virus landscape of AIDS-related lymphomas. Blood. 2015;125(20):e14-22.

49. Walens A, DiMarco AV, Lupo R, Kroger BR, Damrauer JS, Alvarez JV. CCL5 promotes breast cancer recurrence through macrophage recruitment in residual tumors. Elife. 2019;8.

50. Luttichau HR, Johnsen AH, Jurlander J, Rosenkilde MM, Schwartz TW. Kaposi sarcomaassociated herpes virus targets the lymphotactin receptor with both a broad spectrum antagonist vCCL2 and a highly selective and potent agonist vCCL3. J Biol Chem. 2007;282(24):17794-805. 51. Herbst H, Foss HD, Samol J, Araujo I, Klotzbach H, Krause H, et al. Frequent expression of interleukin-10 by Epstein-Barr virus-harboring tumor cells of Hodgkin's disease. Blood. 1996;87(7):2918-29.

52. Sarris AH, Kliche KO, Pethambaram P, Preti A, Tucker S, Jackow C, et al. Interleukin-10 levels are often elevated in serum of adults with Hodgkin's disease and are associated with inferior failure-free survival. Ann Oncol. 1999;10(4):433-40.

53. Lurain K, Polizzotto MN, Aleman K, Bhutani M, Wyvill KM, Goncalves PH, et al. Viral, immunologic, and clinical features of primary effusion lymphoma. Blood. 2019;133(16):1753-61.

54. Bejarano MT, Masucci MG. Interleukin-10 abrogates the inhibition of Epstein-Barr virusinduced B-cell transformation by memory T-cell responses. Blood. 1998;92(11):4256-62. 
55. Jochum S, Moosmann A, Lang S, Hammerschmidt W, Zeidler R. The EBV immunoevasins vIL-10 and BNLF2a protect newly infected B cells from immune recognition and elimination. PLoS Pathog. 2012;8(5):e1002704.

56. Hsu SM, Lin J, Xie SS, Hsu PL, Rich S. Abundant expression of transforming growth factor-beta 1 and -beta 2 by Hodgkin's Reed-Sternberg cells and by reactive T lymphocytes in Hodgkin's disease. Hum Pathol. 1993;24(3):249-55.

57. Tan GW, Visser L, Tan LP, van den Berg A, Diepstra A. The Microenvironment in EpsteinBarr Virus-Associated Malignancies. Pathogens. 2018;7(2).

58. Albanese M, Tagawa T, Bouvet M, Maliqi L, Lutter D, Hoser J, et al. Epstein-Barr virus microRNAs reduce immune surveillance by virus-specific CD8+ T cells. Proc Natl Acad Sci U S A. 2016;113(42):E6467-E75.

59. Murer A, Ruhl J, Zbinden A, Capaul R, Hammerschmidt W, Chijioke O, et al. MicroRNAs of Epstein-Barr Virus Attenuate T-Cell-Mediated Immune Control In Vivo. MBio. 2019;10(1).

60. Pfeffer S, Zavolan M, Grasser FA, Chien M, Russo JJ, Ju J, et al. Identification of virusencoded microRNAs. Science. 2004;304(5671):734-6.

61. Xia T, O'Hara A, Araujo I, Barreto J, Carvalho E, Sapucaia JB, et al. EBV microRNAs in primary lymphomas and targeting of CXCL-11 by ebv-mir-BHRF1-3. Cancer Res. 2008;68(5):1436-42.

62. Coscoy L, Ganem D. Kaposi's sarcoma-associated herpesvirus encodes two proteins that block cell surface display of MHC class I chains by enhancing their endocytosis. Proc Natl Acad Sci U S A. 2000;97(14):8051-6.

63. Ressing ME, van Gent M, Gram AM, Hooykaas MJ, Piersma SJ, Wiertz EJ. Immune Evasion by Epstein-Barr Virus. Curr Top Microbiol Immunol. 2015;391:355-81.

64. Gujer C, Murer A, Muller A, Vanoaica D, Sutter K, Jacque E, et al. Plasmacytoid dendritic cells respond to Epstein-Barr virus infection with a distinct type I interferon subtype profile. Blood Adv. 2019;3(7):1129-44.

65. Ma SD, Hegde S, Young KH, Sullivan R, Rajesh D, Zhou Y, et al. A new model of EpsteinBarr virus infection reveals an important role for early lytic viral protein expression in the development of lymphomas. J Virol. 2011;85(1):165-77.

66. Antsiferova $O$, Müller A, Rämer P, Chijioke O, Chatterjee B, Raykova A, et al. Adoptive transfer of EBV specific CD8 ${ }^{+} \mathrm{T}$ cell clones can transiently control EBV infection in humanized mice. PLoS Pathog. 2014;10(8):e1004333. 
67. Bristol JA, Djavadian R, Albright ER, Coleman CB, Ohashi M, Hayes M, et al. A cancerassociated Epstein-Barr virus BZLF1 promoter variant enhances lytic infection. PLoS Pathog. 2018;14(7):e1007179.

68. Correia S, Bridges R, Wegner F, Venturini C, Palser A, Middeldorp JM, et al. Sequence Variation of Epstein-Barr Virus: Viral Types, Geography, Codon Usage, and Diseases. J Virol. 2018;92(22).

69. Okuno $\mathrm{Y}$, Murata T, Sato $\mathrm{Y}$, Muramatsu H, Ito $\mathrm{Y}$, Watanabe $\mathrm{T}$, et al. Defective EpsteinBarr virus in chronic active infection and haematological malignancy. Nat Microbiol. 2019;4(3):404-13.

70. Uldrick TS, Polizzotto MN, Aleman K, O'Mahony D, Wyvill KM, Wang V, et al. High-dose zidovudine plus valganciclovir for Kaposi sarcoma herpesvirus-associated multicentric Castleman disease: a pilot study of virus-activated cytotoxic therapy. Blood. 2011;117(26):6977-86.

71. Martin DF, Kuppermann BD, Wolitz RA, Palestine AG, Li H, Robinson CA. Oral ganciclovir for patients with cytomegalovirus retinitis treated with a ganciclovir implant. Roche Ganciclovir Study Group. N Engl J Med. 1999;340(14):1063-70.

72. Robles R, Lugo D, Gee L, Jacobson MA. Effect of antiviral drugs used to treat cytomegalovirus end-organ disease on subsequent course of previously diagnosed Kaposi's sarcoma in patients with AIDS. J Acquir Immune Defic Syndr Hum Retrovirol. 1999;20(1):34-8.

73. Marquet J, Velazquez-Kennedy K, Lopez S, Benito A, Blanchard MJ, Garcia-Vela JA. Case report of a primary effusion lymphoma successfully treated with oral valganciclovir after failing chemotherapy. Hematol Oncol. 2018;36(1):316-9.

74. Casagrande N, Borghese C, Visser L, Mongiat M, Colombatti A, Aldinucci D. CCR5 antagonism by maraviroc inhibits Hodgkin lymphoma microenvironment interactions and xenograft growth. Haematologica. 2019;104(3):564-75.

75. Uldrick TS, Wyvill KM, Kumar P, O'Mahony D, Bernstein W, Aleman K, et al. Phase II study of bevacizumab in patients with HIV-associated Kaposi's sarcoma receiving antiretroviral therapy. J Clin Oncol. 2012;30(13):1476-83.

76. Laubach J, Richardson P, Anderson K. Multiple myeloma. Annu Rev Med. 2011;62:24964.

77. Siddiqi T, Joyce RM. A case of HIV-negative primary effusion lymphoma treated with bortezomib, pegylated liposomal doxorubicin, and rituximab. Clin Lymphoma Myeloma. 2008;8(5):300-4.

78. Muzes G, Sipos F, Csomor J, Sreter L. Successful tocilizumab treatment in a patient with human herpesvirus 8-positive and human immunodeficiency virus-negative multicentric 
Castleman's disease of plasma cell type nonresponsive to rituximab-CVP therapy. APMIS. 2013;121(7):668-74.

79. Nagao A, Nakazawa S, Hanabusa H. Short-term efficacy of the IL6 receptor antibody tocilizumab in patients with HIV-associated multicentric Castleman disease: report of two cases. J Hematol Oncol. 2014;7:10.

80. Linnerbauer S, Behrends U, Adhikary D, Witter K, Bornkamm GW, Mautner J. Virus and autoantigen-specific CD4 ${ }^{+} \mathrm{T}$ cells are key effectors in a SCID mouse model of EBV-associated post-transplant lymphoproliferative disorders. PLoS Pathog. 2014;10(5):e1004068.

81. van Zyl DG, Tsai MH, Shumilov A, Schneidt V, Poirey R, Schlehe B, et al. Immunogenic particles with a broad antigenic spectrum stimulate cytolytic $T$ cells and offer increased protection against EBV infection ex vivo and in mice. PLoS Pathog. 2018;14(12):e1007464. 


\section{Figure legend}

Figure 1: Conditioning of the tumor microenvironment of EBV and KSHV associated malignancies. The microenvironment of both EBV (left) and KSHV (right) associated malignancies is composed of a mixture of latently and early lytically (BZLF1 or Rta) infected cells. Early lytic replication conditions the microenvironment of both EBV and KSHV associated malignancies by attracting monocytes to differentiate into immune suppressive tumor associated macrophages (TAM) via CCL5 or viral macrophage inflammatory proteins (VMIP). Furthermore, viral IL-10 (vlL-10) suppresses immune activation in the microenvironment of EBV associated malignancies and viral IL-6 (vlL-6) induces plasma cell differentiation in KSHV associated malignancies. EBV further suppresses CD8+ $\mathrm{T}$ cell mediated immune control by blocking CXCL11 mediated attraction of $\mathrm{CD}^{+} \mathrm{T}$ cells and down-regulation of $\mathrm{MHC}$ class I restricted antigen presentation with its miRNAs that are expressed during latency and lytic infection. Early lytic $\mathrm{KSHV}$ infection is pro-angiogenic, triggering vascular endothelial growth factor (VEGF), plateletderived growth factor (PDGF) and angiopoietin 2 (ANGPT2) production. 


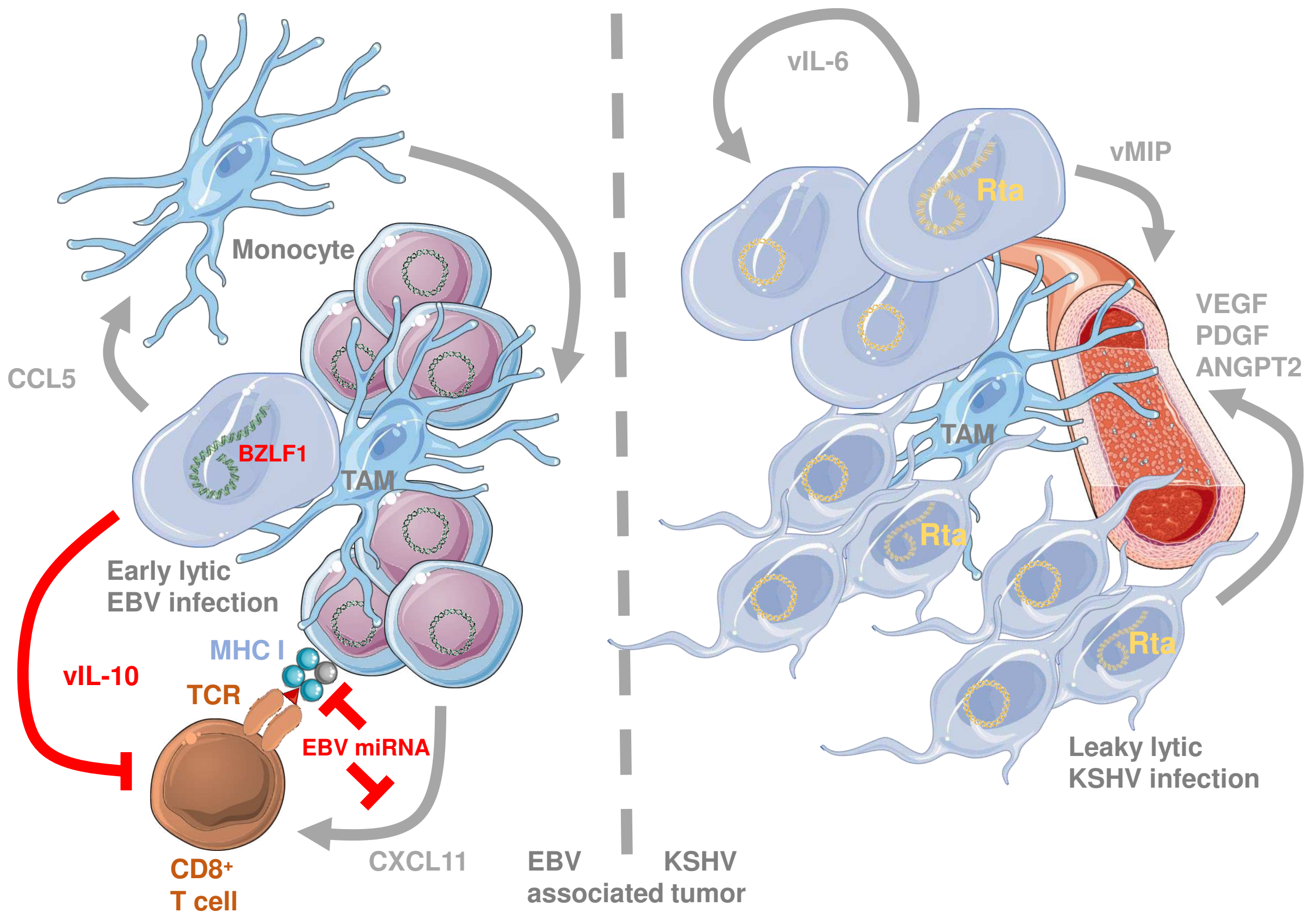

\section{Figure 1}

